\title{
Severe hypokalaemia with paralysis induced by small doses of liquorice
}

\author{
A. M. M. Cumming \\ R.C.N. \\ K. BoDDY \\ Ph.D. \\ J. J. BROWN \\ M.B., F.R.C.P. \\ R. FraSER \\ Ph.D. \\ A. F. LEVER \\ M.B., F.R.C.P. \\ P. L. PADFIELD $\dagger$
M.B., M.R.C.P. \\ J. I. S. ROBERTSON* \\ M.B., F.R.C.P. \\ ${ }^{*} M R C$ Blood Pressure Unit, and $†$ Department of Medicine, Western Infirmary, Glasgow G11 6NT
}

\begin{abstract}
Summary
A patient, who presented with a flaccid quadriplegia due to profound hypokalaemia, is described. Hypokalaemia and myoglobinuria were caused by the ingestion of small amounts of liquorice contained in a laxative preparation. Subsequent controlled administration of small amounts of this preparation induced marked hypokalaemia. This was associated with sodium retention and potassium loss confirming a mineralocorticoid-like action. The sodium retention was associated with suppression of plasma levels of renin and aldosterone.
\end{abstract}

\section{Introduction}

Liquorice extracts are prepared from the root of the plant Glycyrrhiza glabra, and contain a principal glycyrrhizic acid which has an action resembling that of mineralocorticoids. The effects of liquorice ingestion may therefore include hypertension, hypokalaemia, hypernatraemia and a fall in plasma renin and aldosterone (Molhuysen et al., 1950; Louis and Conn, 1956; Salassa, Mattox and Rosevear, 1962; Gross, Dexter and Roth, 1966; Conn, Rovner and Cohen, 1968; Holmes et al., 1970; Epstein et al., 1977a, b; Bannister, Ginsburg and Shneerson, 1977). The dangers of injudicious use of liquorice-containing preparations are probably well known to most clinicians, although it is generally thought that substantial quantities (upwards of one $\mathrm{g}$ daily of glycyrrhizic acid), often for prolonged periods, are needed to cause severe metabolic disturbance.

The present paper describes a patient who

Reprint requests to: Dr J. I. S. Robertson, MRC Blood Pressure Unit, Western Infirmary, Glasgow G11 6NT. appeared unusually sensitive to a liquorice preparation, the diagnosis being confirmed by its subsequent $c$ administration under controlled circumstances.

\section{Case history}

A 70-year-old white woman had been well fô. most of her life apart from an above-knee left legg amputation in 1934 following a road accident. She complained of a lack of energy throughout 1973, and $\frac{\varnothing}{\varnothing}$ in November that year she was admitted to hospital $\cong$ for investigation. BP was $200 / 100 \mathrm{mmHg}$. She had a $\overrightarrow{\overrightarrow{0}}$ normochromic normocytic anaemia $(\mathrm{Hb} 10 \mathrm{~g} / \mathrm{dl}$ ), 3 a serum potassium and sodium concentration of $1.7 \mathrm{mmol} / \mathrm{l}$ and $145 \mathrm{mmol} / 1$ respectively. She was given oral potassium chloride and discharged $\overline{7}$ without follow-up.

In February 1974 she was re-admitted to the same hospital as an emergency, having fallen and been unable to rise. She had been unwell for the previous month with nausea, occasional vomiting and progressive muscular weakness. BP was $180 / 80$ 은 $\mathrm{mmHg}$, serum potassium $1.1 \mathrm{mmol} / \mathrm{l}$, sodium $140 \mathrm{mmol} / \mathrm{l}$ and urea $10 \mathrm{mmol} / \mathrm{l}$.

Initial therapy consisted of i.v. potassium supple- $\widetilde{N}$ ments, together with oral spironolactone.

She was transferred to the MRC Blood Pressure 0 Unit 3 days later. There was a complete flaccid $\omega$ paralysis of all limbs, with an inability to lift the head; tendon reflexes and the cough reflex were $\stackrel{0}{\varnothing}$ absent and the gag reflex was very weak. BP was $182 / 92 \mathrm{mmHg}$, serum potassium concentration was $\stackrel{+}{-}$ $1.2 \mathrm{mmol} / \mathrm{l}$, sodium $148 \mathrm{mmol} / \mathrm{l}$, bicarbonate 33 뭉 $\mathrm{mmol} / \mathrm{l}$ and urea $18 \mathrm{mmol} / \mathrm{l}$. Serum lactic dehydro- $\stackrel{\vec{D}}{\mathbb{D}}$ genase was markedly elevated at $1000 \mathrm{u}$./l. Plasma 
aldosterone was low at $55 \mathrm{pmol} / 1$ (normal up to 500 pmol/l). Electrocardiography revealed changes typical of severe hypokalaemia with flattened Twaves and prominent U-waves. Urine was red in colour, contained no red cells and, when fractionated by gel filtration (Sephadex G75) it was shown that the red pigment was predominantly myoglobin with a trace of $\mathrm{Hb}$. It was concluded that the raised serum levels of lactic dehydrogenase and the presence of myoglobin in urine resulted from necrosis of muscle.

Initial therapy consisted of i.v. potassium replacement combined with spironolactone given via nasogastric tube. Four days after admission, when serum potassium was $2.5 \mathrm{mmol} / 1$, muscle biopsy suggested a toxic or metabolic myopathy with fibre vacuolation. Myoglobin disappeared from the urine within 4 days of admission. Serum potassium rose to $4.0 \mathrm{mmol} / \mathrm{l}$ and subsequent progress was uneventful.

The patient later admitted that she had for 2-3 years taken intermittently small amounts of a liquorice-containing mixture, apparently as a laxative. This medicine was found to contain equal amounts of liquorice liquid extract B.P., cascara, elixir B.P. and liquid paraffin B.P. The patient would admit to taking no more than 2 or 3 teaspoonfuls of this preparation per week. Five $\mathrm{ml}$ was calculated to contain $47 \mathrm{mg}$ of the calcium and potassium salts of glycyrrhizic acid.

\section{Liquorice administration under controlled circum- stances}

Because it appeared probable that the severe hypokalaemia was due to ingestion of liquorice, its effects were studied under control conditions.

In April 1975 the patient was placed on a fixed diet containing $134 \mathrm{mmol}$ of sodium and $38 \mathrm{mmol}$ of potassium daily for 25 days, during which time all urine and faeces were collected. During the first 7 days no addition therapy was given, then for 11 days the patient took her own liquorice preparation in a dose of $5 \mathrm{ml}$ twice daily. This treatment was then stopped for the final period of 7 days. At no time did the patient experience symptoms. Measurements were made of serum, urinary and faecal electrolytes throughout the study (routine automated analysis). Plasma renin (Brown et al., 1964) and aldosterone (Fraser, Guest and Young, 1973) concentrations were also measured before and during liquorice administration. Peripheral venous blood samples for these purposes were drawn between 8.30 and 9.30 a.m. after overnight recumbency and fasting. Exchangeable sodium and potassium were measured before and during liquorice administration by the method of Davies and Robertson (1973).

\section{Results of special studies}

Faeces were not analysed during the beginning of the run-in period, but over the last 3 days of the initial 7-day period without medication, mean output of sodium in stool and urine was $105 \mathrm{mmol}$ and potassium $37.5 \mathrm{mmol} /$ day. The administration of liquorice, although it did not provoke diarrhoea, enhanced the faecal output of potassium with perhaps minimal increases in faecal sodium (Fig. 1).
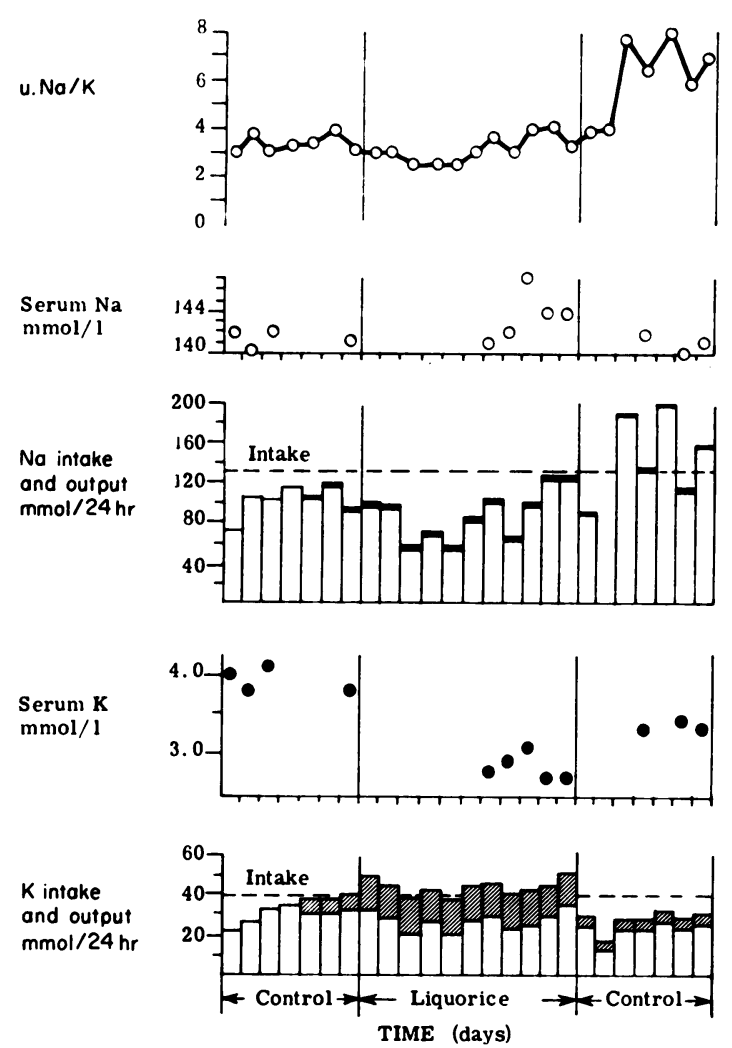

FIG. 1. Changes in serum sodium and potassium, and in sodium and potassium balance, induced by 11 days' medication with liquorice-containing mixture. Dietary intake of sodium and potassium indicated. Urinary output of sodium and potassium is shown by open columns; faecal output by filled and hatched columns respectively. No faecal electrolytes were available for the first 4 days of the study.

These increased faecal losses persisted throughout the 11 days in which liquorice was given. Over the same period the urinary output of sodium was markedly reduced, with a slight fall in urine potassium. The relative losses of urinary and faecal sodium and potassium were different, however, so that there was a measured net external loss of 48 mmol of potassium and a measured net retention of $228 \mathrm{mmol}$ of sodium. Towards the end of the period 
of liquorice administration, the patient came into sodium balance ('mineralocorticoid escape'). After stopping the liquorice preparation, urine sodium increased significantly with a concomitant fall in urinary potassium. Faecal losses reverted to the pre-liquorice pattern (Fig. 1). There was a tendency for the urinary sodium/potassium ratio to fall during the initial days of liquorice administration, but to rise slightly thereafter ('escape') and rebound to much greater than baseline value when the liquorice was stopped (Fig. 1). Total exchangeable electrolyte measurements suggested rather larger changes in electrolyte balance, exchangeable sodium increasing from 2303 to $2703 \mathrm{mmol}$ and exchangeable potassium falling from 1464 to $1144 \mathrm{mmol}$. These changes probably reflect more closely the magnitude of the induced changes since daily errors in external balance data can lead to large cumulative inaccuracies over prolonged studies (Forbes and Perley, 1951; Edelman et al., 1952; Miller and Wilson, 1953). Liquorice administration resulted in a marked fall in serum potassium concentrations to levels below $3 \mathrm{mmol} / \mathrm{l}$, while serum sodium increased. Plasma concentrations of renin and aldosterone before and at the end of the period of liquorice administration were, respectively, 64 and $35 \mu \mathrm{u}$./ml (normal range $20-120 \mu \mathrm{u} . / \mathrm{ml})$ and 110 and $55 \mathrm{pmol} / \mathrm{l}$. BP did not change significantly during liquorice administration. Serum sodium and potassium reverted to pretreatment levels during the period following liquorice administration.

\section{Subsequent course}

In the 4 years since these studies were completed, the patient has avoided her liquorice-containing laxative and has remained well, with normal levels of serum potassium.

\section{Discussion}

There seems little doubt that the liquoricecontaining medicine was responsible for this patient's severe illness with profound hypokalaemia. She has remained well at all times when avoiding the drug, while trial exposure to it under controlled circumstances provoked hypokalaemia, with potassium loss and sodium retention. Myoglobinuria in her initial severe illness was almost certainly due to hypokalaemic-induced myopathy, as has been reported previously in association with both liquorice (Gross et al., 1966) and carbenoxolone (Mohammed, Chapman and Crooks, 1966; Forshaw, 1969) administration.

A remarkable aspect of the present patient was her response to small doses of liquorice in comparison with previously reported cases.

Louis and Conn (1956) gave 7 normal subjects 2 to $5 \mathrm{~g}$ /day of ammonium glycyrrhizate for 3 days. They observed marked sodium retention with mild kaliuresis.

Conn et al. (1968) described a patient who was calculated to have taken the equivalent of about $0.5 \mathrm{~g}$ ammonium glycyrrhizate for 6-7 years. This man did not apparently develop hypokalaemia until first chlorothiazide and then chlorthalidone therapy was given. This same patient was given ammonium glycyrrhizate one mg/day for 2 days, followed by 2 $\mathrm{g} /$ day for 3 days and finally $4 \mathrm{~g} /$ day for 5 days. This induced sodium retention, a rise in BP, with a fall in plasma renin and in aldosterone excretion. Kaliuresis was mild, while serum potassium fell from 4.6 to a nadir of $3.5 \mathrm{mmol} / 1$.

Epstein et al. (1977b) gave 14 normal volunteers the equivalent of $0.7-1.4 \mathrm{~g}$ glycyrrhizic acid daily for one to 4 weeks. This induced significant depression of plasma levels of renin, angiotensin II, aldosterone and potassium. However, the lowest plasma potassium concentration in the whole series, seen at the $1.4 \mathrm{~g}$ daily dose, was $3.0 \mathrm{mmol} / \mathrm{l}$.

In the present patient, as little as $94 \mathrm{mg}$ of the calcium and potassium salts of glycyrrhizic acidô given daily for 11 days, was sufficient to induces profound hypokalaemia. Despite the lack of obvious increase in urine potassium excretion over this period, the slight fall in urinary $\mathrm{Na}: \mathrm{K}$ ratio with the marked rebound rise in this ratio after discontinuation of the liquorice strongly suggests a mineralocorticoid effect, although a small laxative effect appears to have occurred also. More importantly, the demonstrated rise in total exchangeable sodium with a concomitant fall in total exchangeable potassium is strongly suggestive of mineralocorticoid activity. It appeared that no more than $100-150 \mathrm{mg}$ of liquorice/week, taken at home for more prolonged periods, was responsible for her severe illness. Whereas some subjects probably continue to consume liquorice surreptitiously and in large quantities even after they have been warned of the dangers, this did not seem likely in the present patient, who has avoided the drug subsequently. There seems no reason to doubt the accuracy of her estimates of the amount she previously took.

Epstein et al. (1977b) have shown that normal subjects vary considerably in their ability to cope with liquorice and have speculated that small doses taken regularly for prolonged periods might in susceptible persons cause severe metabolic disturbance. This seems to have been the case in the patient described here. 


\section{References}

Bannister, B., Ginsburg, R. \& Shneerson, J. (1977) Cardiac arrest due to liquorice-induced hypokalaemia. British Medical Journal, 2, 738.

Brown, J.J., Davies, D.L., Lever, A.F., Robertson, J.I.S. \& TREE, M. (1964) The estimation of renin in human plasma. Biochemical Journal, 93, 594.

ConN, J.W., Rovner, D.R. \& CoHEN, E.L. (1968) Liquoriceinduced pseudoaldosteronism: hypertension, aldosteronopenia and suppressed plasma renin activity. Journal of the American Medical Association, 205, 492.

Davies, D.L. \& Robertson, J.W.K. (1973) Simultaneous measurement of total exchangeable potassium and sodium using ${ }^{43} \mathrm{~K}$ and ${ }^{24} \mathrm{Na}$. Metabolism, 22, 133.

Edelman, I.S., Olney, J.M., James, A.H., Brooks, L. \& Moore, F.D. (1952) Body composition: studies in the human being by the dilution principle. Science, 115, 447.

Epstein, M.T., Espiner, E.A., Donald, R.A. \& Hughes, H. (1977a) Liquorice toxicity and the renin-angiotensinaldosterone axis in man. British Medical Journal, 1, 209.

Epstein, M.T., Espiner, E.A., Donald, R.A. \& Hughes, H. (1977b) Effect of eating liquorice on the renin-angiotensin-aldosterone axis in normal subjects. British Medical Journal, 1, 488.

Forbes, G.B. \& Perley, A. (1951) Estimation of total body sodium by isotope dilution: II-studies on infants and children: an example of a constant differential growth ratio. Journal of Clinical Investigation, 30, 566.

Forshaw, J. (1969) Muscle paresis and hypokalaemia after treatment with duogastrone. British Medical Journal, 2, 674.
Fraser, R., Guest, S. \& Young, J. (1973) A comparison of double-isotope derivative and radioimmunological estimation of plasma aldosterone in man. Clinical Science and Molecular Medicine, 45, 411.

Gross, E.G., Dexter, J.D. \& Roth, R.G. (1966) Hypokalaemic myopathy with myoglobinuria associated with licorice ingestion. New England Journal of Medicine, 274, 602.

Holmes, A.M., Marrott, P.K., Young, J. \& Prentice, E. (1970) Pseudohyperaldosteronism induced by habitual ingestion of liquorice. Postgraduate Medical Journal, 46, 625.

Louis, L.H. \& ConN, J.W. (1956) Preparation of glycyrrhizinic acid, the electrolyte-active principle of licorice; its effects upon metabolism and upon pituitary-adrenal function in man. Journal of Laboratory and Clinical Medicine, 47, 20.

Miller, H. \& Wilson, G.M. (1953) The measurement of exchangeable sodium in man using the isotope ${ }^{24} \mathrm{Na}$. Clinical Science, 12, 97.

Mohammed, S.D., Chapman, R.S. \& Crooks, J. (1966) Hypokalaemia, flaccid quadruparesis and myoglobinuria with carbenoxolone (biogastrone). British Medical Journal, $1,1581$.

Molhuysen, J.A., Gerbrandy, J., de Vries, L.A., DE JonG, J.C., Lenstra, J.B., Turner, K.P. \& BORst, J.G.G. (1950) A liquorice preparation with deoxycortone-like action. Lancet, ii, 381.

Salassa, R.M., Mattox, V.R. \& Rosevear, J.W. (1962) Inhibition of the 'mineralocorticoid' activity of licorice by spironolactone. Journal of Clinical Endocrinology and Metabolism, 22, 1156. 